\title{
Magnetic Measurements of the Elliptical Multipole Wiggler Prototype
}

\author{
by D. Frachon, I. Vasserman, P. M. Ivanov, \\ E. A. Medvedko, E. Gluskin, and \\ N. A. Vinokurov
}

March 1995

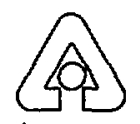


Argonne National Laboratory, with facilities in the states of Illinois and Idaho, is owned by the United States government, and operated by The University of Chicago under the provisions of a contract with the Department of Energy.

\section{DISCLAIMER}

This report was prepared as an account of work sponsored by an agency of the United States Government. Neither the United States Govemment nor any agency thereof, nor any of their employees, makes any warranty, express or implied, or assumes any legal liability or responsibility for the accuracy, completeness, or usefulness of any information, apparatus, product, or process disclosed, or represents that its use would not infringe privately owned rights. Reference herein to any specific commercial product, process, or service by trade name, trademark, manufacturer, or otherwise, does not necessarily constitute or imply its endorsement, recommendation, or favoring by the United States Government or any agency thereof. The views and opinions of authors expressed herein do not necessarily state or reflect those of the United States Government or any agency thereof.

Reproduced from the best available copy.

Available to DOE and DOE contractors from the

Office of Scientific and Technical Information

P.O. Box 62

Oak Ridge. TN 37831

Prices available from (615) 576-8401

Available to the public from the

National Technical Information Service

U.S. Department of Commerce

5285 Port Royal Road

Springfieid. VA 22161 
Distribution Category: Atomic, Molecular, and Chemical Physics (UC-411)

\section{ARGONNE NATIONAL LABORATORY 9700 South Cass Avenue \\ Argonne, Illinois 60439}

ANL/APS/TB-22

\section{Magnetic Measurements of the Elliptical Multipole Wiggler Prototype}

D. Frachon, I. Vasserman, P. M. Ivanov,

E. A. Medvedko, E. Gluskin,

Experimental Facilities Division

Advanced Photon Source.

and N. A. Vinokurov

Budker Institute of Nuclear Physics, Novosibirsk, Russia

March 1995

work sponsored by

U.S. DEPARTMENT OF ENERGY

Office of Energy Research 
D. Frachon, I. Vasserman, P. M. Ivanov, E. A. Medvedko, E. Gluskin

a n d

N. A. Vinokurov

\section{Magnetic Measurements of the Elliptical Multipole Wiggler Prototype}

\section{TABLE OF CONTENTS}

1. Introduction

2. Magnetic Measurement Technique

3. Measurement Results of the First and Second Field Integrals

4. Conclusion 


\section{Introduction}

A prototype of the elliptical multipole wiggler (EMW) [1] has been assembled, tested, and magnetically tuned at the APS. This prototype has a period of 160 $\mathrm{mm}$ with seven poles for the hybrid structure (antisymmetric configuration) and ten poles for the electromagnetic part of the EMW (symmetric configuration). The hybrid structure of the EMW produces a vertical magnetic field of $0.83 \mathrm{~T}\left(\mathrm{~K}_{\mathrm{y}}=12\right)$ for a gap of $27 \mathrm{~mm}$, and the electromagnet structure provides a maximum horizontal field of $0.12 \mathrm{~T}\left(\mathrm{~K}_{\mathrm{x}}=1.6\right)$ with $\mathrm{AC}$ frequency up to $100 \mathrm{~Hz}$. The alternation time is about $3 \mathrm{~ms}$.

The requirements for electromagnetic field quality are very tight because the EMW introduces orbit perturbations in the vertical plane, where the emittance is smallest. Also the storage ring correction system cannot respond to perturbations of more than $10 \mathrm{~Hz}$ frequency. Thus the main effort during the magnetic tuning of the EMW was directed toward establishing time independence of the magnetic field integrals to better than $2 \mathrm{G}-\mathrm{cm}$ while the current was alternating through the electromagnet. This time independence has been achieved by implementing a special field integral compensation system and novel fast magnetic measurement techniques.

Magnetic measurements of the EMW prototype have been performed at the APS insertion device magnetic measurement facility [2]. A new fast acquisition system with a maximum sampling rate of $1 \mathrm{MHz}$ has been developed and used for these measurements. Also a novel "twisted coil" technique has been used in order to make fast measurements of the second field integral. The field integral compensation on the order of $1 \mathrm{G}-\mathrm{cm}$ and $1000 \mathrm{G}-\mathrm{cm}^{2}$ for the first and second integrals, respectively, has been achieved at electromagnet $\mathrm{AC}$ frequencies up to $100 \mathrm{~Hz}$.

\section{Magnetic Measurement Technique}

The EMW with an electromagnet operated at up to $100 \mathrm{~Hz}$ represents a challenge for precision magnetic measurements, especially for the measurements of the second field integrals. Conventional methods of second field integral measurements are based on the step by step translation of magnetic sensors, such as Hall probes or small coils, along the main axis of the EMW. and with measurements taken at every step. These measurements take too long for there to be any possibility of measuring the time dependence of 
the field. Therefore a novel technique was introduced and used for the fast and precise magnetic measurements of second field integrals.

The stretched coil conventional configuration with parallel wires [3] has been used to measure the first field integrals. In order to conduct fast measurements, however, two boards stet: a CTM05 board and a FastADC board, have been installed on the PC bus. The first generates pulses to define the frequency of the power supply, i.e., the $\mathrm{AC}$ frequency, and to trigger the FastADC board to synchronize magnetic measurements. Fig. 1 presents a layout of this configuration. A typical sampling time of $0.1 \mathrm{~ms}$ has been used for the $\mathrm{AC}$ frequency of $100 \mathrm{~Hz}$.

In order to measure the second field integral, a novel long coil configuration $w$ proposed by one of us (N.V.) and then developed and implemented for the EM measurements. The long coil has been twisted by $180^{\circ}$, as shown in Fig. 2 .

The magnetic flux in that case is defined from the following expression:

$$
\begin{gathered}
\Phi=\int_{-L}^{L} \Theta \cdot z \cdot B(z) d z=\left.\Theta \cdot z \cdot \int_{-L}^{L} B\left(z^{\prime}\right) d z^{\prime}\right|_{-L} ^{L}-\int_{-L}^{L} \Theta \cdot I_{1}\left(z^{\prime}\right) d z^{\prime}= \\
=\Theta\left[L \cdot I_{1}(L)-I_{2}(L)\right],
\end{gathered}
$$

where:

$$
\Theta=\frac{d}{L} ; \quad I_{1}(z)=\int_{-L}^{z} B\left(z^{\prime}\right) d z^{\prime} ; \quad I_{2}(z)=\int_{-L}^{z} I_{1}\left(z^{\prime}\right) d z^{\prime}
$$

Unlike for the conventional long coil configuration, the magnetic flux now depends on both the first and second field integrals.

From the expression for the magnetic flux, one can obtain:

$$
I_{2}(L)=-\frac{\Phi}{\Theta}+L \cdot I_{1}(L)
$$

This expression becomes especially simple when the first field integral is equal or close to zero and it is exactly what we have in our case. 


\section{FAST MAGNETIC MEASUREMENTS CONFIGURATION}

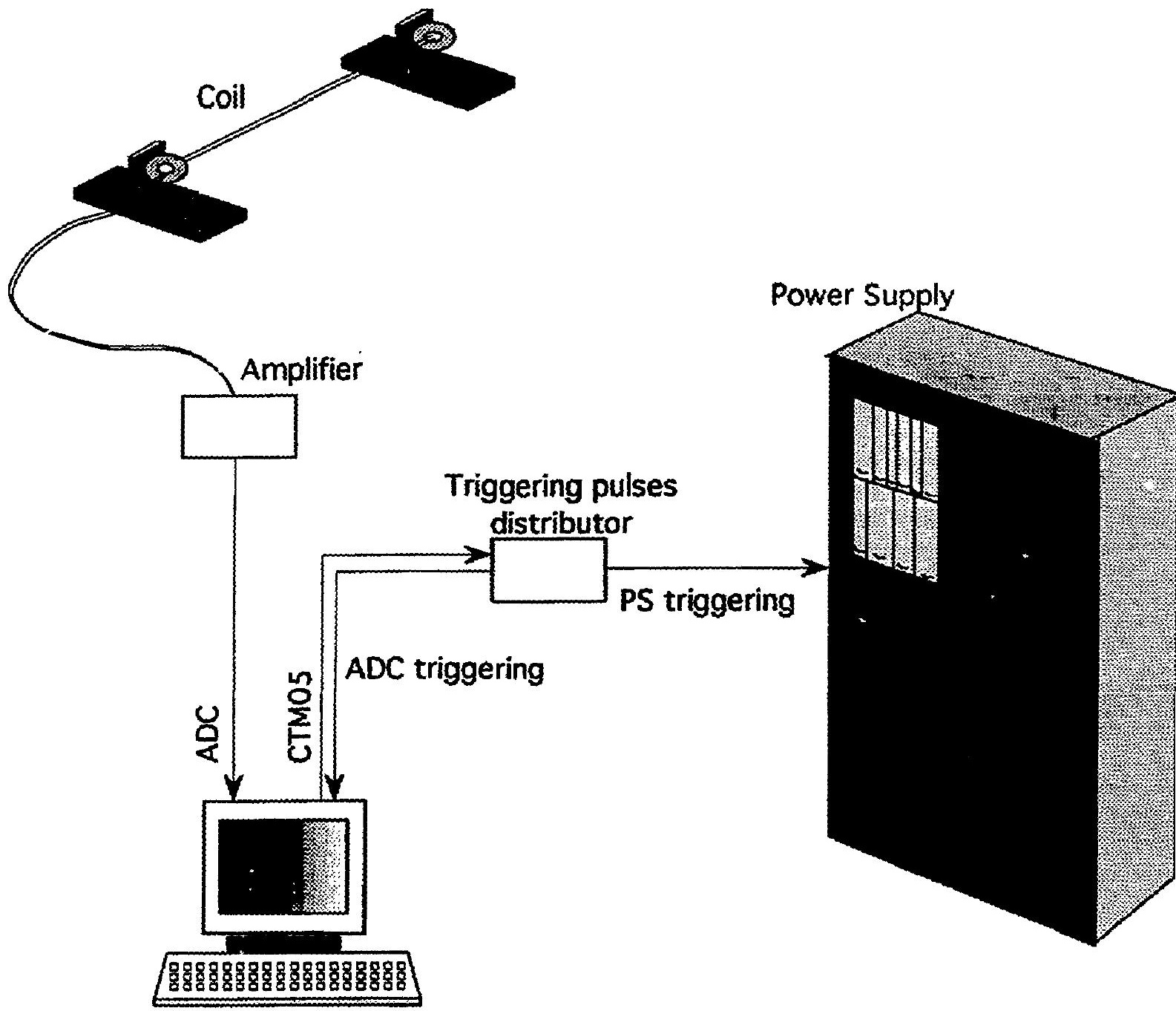

RESOLUTION: 8 SAMPLINGS PER MILLISECOND

Figure 1 


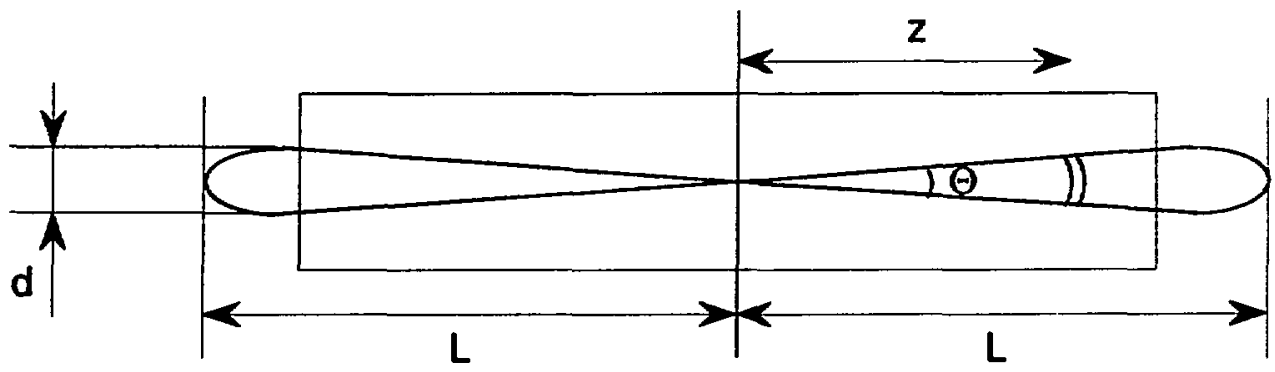

Fig. 2 Long Coil Configuration for Second Field Integral Measurements

\section{Measurement Results for the First and Second Field Integrals}

Two types of correction systems have been used to compensate for the AC dependence of the horizontal field integrals.

The first one, a passive (i.e., non dynamic) correction system, includes a manually adjustabie magnetic gap for the two last poles at each end of the electromagnetic structure. The first field integral can be adjusted by decreasing the magnetic gap for the last pole at the end of the wiggler and increasing the gap for the last pole at the other end. This adjustment also affects the second field integral. The second field integral is adjusted by increasing (or decreasing) the magnetic gap equally at both ends of the wiggler. Since there is an even number of poles in the electromagnetic structure, this adjustment has no effect on first field integral. Finally, the gap for the next-to-last poles at both ends were chosen to make the trajector; of the beam as close to the axis of the device as possible.

The active or dynamic correction system is based on the use of a set of two correction coils mounted on each end of the electromagnetic structure. These coils are fed by the a power supply with an arbitrary function generator [4].

The results of the compensation of the first and second horizontal field integrals for an $\mathrm{AC}$ frequency of $100 \mathrm{~Hz}$ are shown in Fig. 3. The peak to peak variation of the first field integral during a $10-\mathrm{ms}$ period is about $10 \mathrm{G}-\mathrm{cm}$ with the dynamic compensation off and less than $1 \mathrm{G}-\mathrm{cm}$ with the dynamic compensation on. The results for the second horizontal field integral are 4000 G-cm ${ }^{2}$ and $1000 \mathrm{G}-\mathrm{cm}^{2}$, correspondingly.

Similar results for the first and second vertical field integrals are shown in Fig. 4. There was no active correction system for the vertical field integral at 

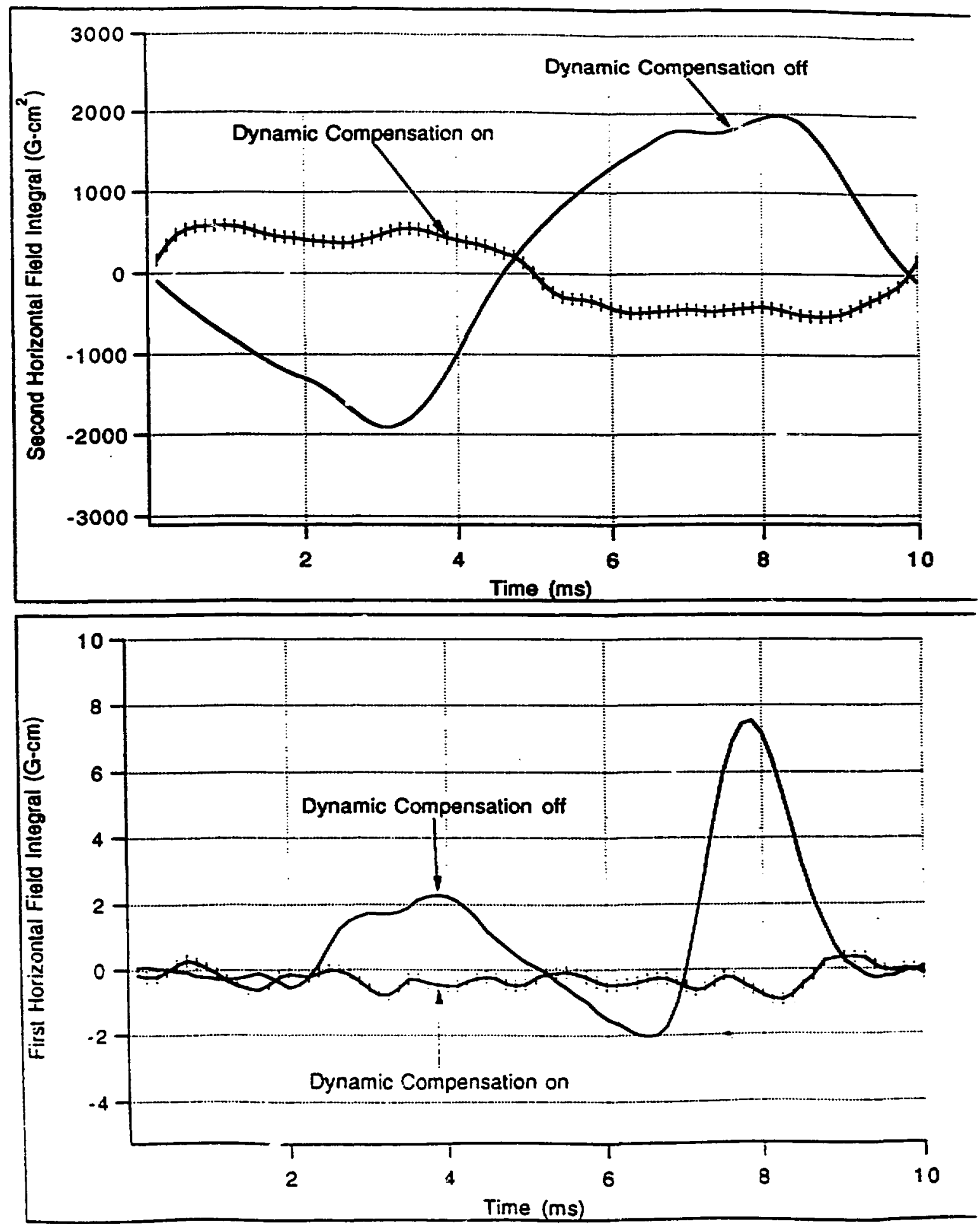

Fig. 3. Time Dependence of First and Second Horizoncal Field Integrals for $100 \mathrm{~Hz}$ Frequency 

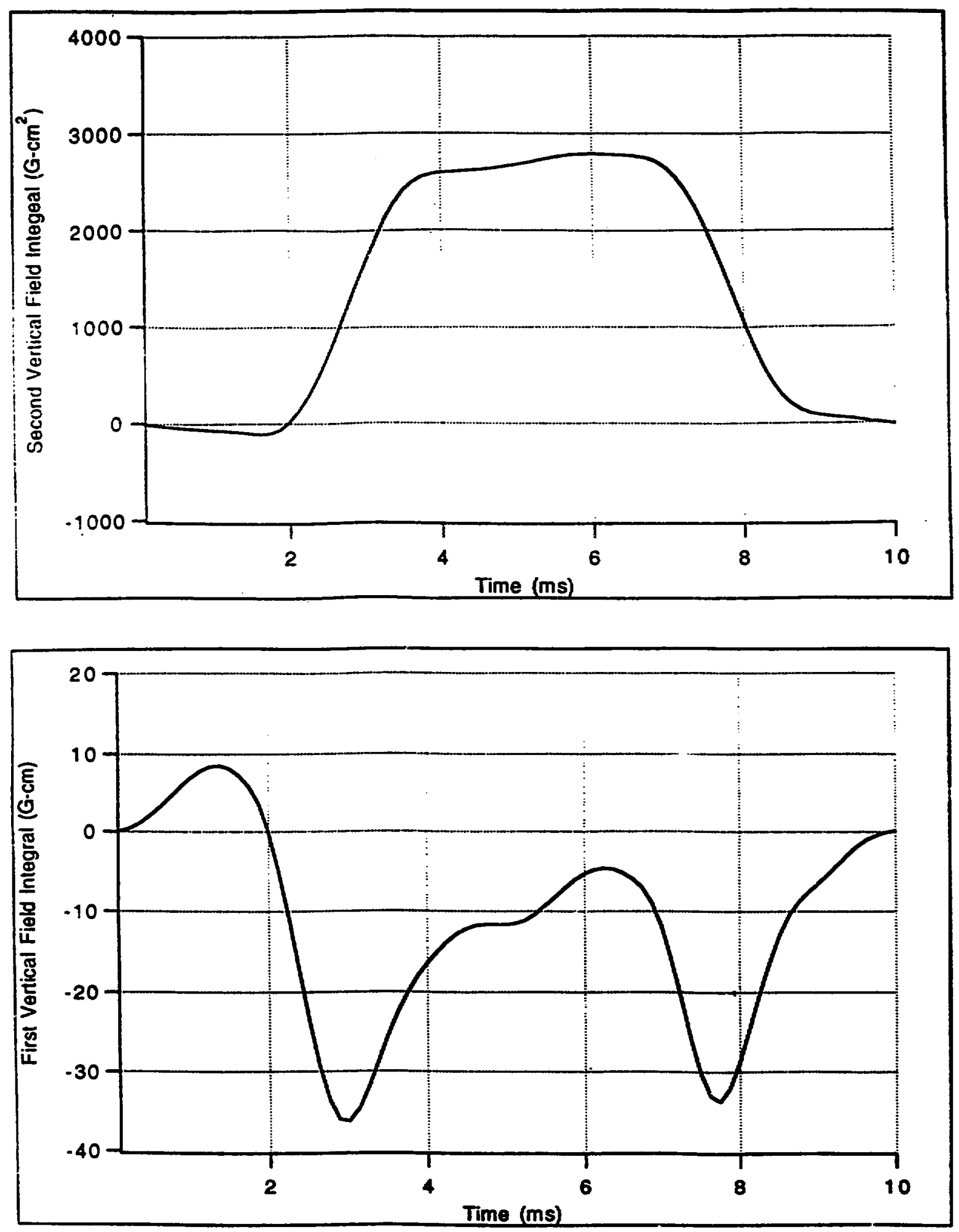

Fig. 4. Time Dependence of First and Second Vertical Field Integrals for $100 \mathrm{~Hz}$ Frequency 
the time of measurements. This system is under construction now and will be incorporated into the EMW later.

\section{Conclusion}

The magnetic measurements and magnetic tuning of the EMW were started in the middle of October 94. New magnetic measurement techniques have been developed and used that allowed completion of all measurements and tuning within a period of one month. The EMW was installed at the NSLS x-ray ring in December 94, and the first tests of the device in February 95 have shown the predicted performance.

References:

1. E. Gluskin et al. "A Status of the Elliptical Multipole Wiggler Project" SRI 94, International Conference, Abstracts, July, 1994

2. 1. L. Burkel, R. Dejus, J. Maines, J. O'Brien, J. Pflüger, and I. Vasserman ANL/APS/Ti3-12, March, 1993

3. D. Frachon, "Developpement de Bancs de Measure Magnetique pour Ondulateurs et Wigglers". Thesis, April 1992

4. O. D. Despe, "Arbitrary Function Generator for APS Injector Synchrotron Correction Magnets", ANL Light-Source Note, LSN-158, November 1990. 